\title{
The Effect of Head Rotation on Intraocular Pressure in Prone Position: a Randomized Trial
}

\author{
M. Nuri Deniz* 1, Arzum Erakgün ', Nezih Sertöz 1, Suzan Güven Yılmaz 2, Halil Ateș ${ }^{2}$, \\ Elvan Erhan ${ }^{1}$
}

1. MD; Ege University School of Medicine Department of Anesthesiology and Reanimation

2. MD; Ege University School of Medicine Department of Ophthalmology

Received from Ege University school of Medicine Department of Anesthesiology and Reanimation, Turkey.

Submitted on November 16, 2011. Approved on March 21, 2012.

\section{Keywords:}

Intraocular Pressure;

Head Movements;

Rotation;

Prone position.

\begin{abstract}
Background and objectives: The increased intraocular pressure (IOP) - which decreases perfusion pressure on the optic nerve - increases by prone positioning (1). The aim of our study was to compare the effect of head rotation $45^{\circ}$ laterally in prone position on the increase in IOP of upper placed and lower placed eyes in patients undergoing percutaneous nephrolithotomy (PCNL). Methods: Forty-five patients were randomly divided into 2 Groups. IOP of the patients were recorded bilaterally in supine position before the operation had started. Patients were turned to prone position. The head was placed on a prone headrest without external direct compression to both eyes. Patients in Group I were kept in strictly neutral prone position where as patients in Group II were placed prone with their heads rotated $45^{\circ}$ laterally to the right side. At the end of the operation, patients were turned to supine position and their IOP was measured immediately. Results: There was no difference related to demographics, duration of surgery, blood loss and fluid input data. IOP values after surgery in prone position increased significantly compared to preoperative values in both groups $(\mathrm{p}<0.05)$. After surgery in prone position IOP values of the upper positioned eyes in Group II were significantly lower than Group I and lower positioned eyes in Group II $(\mathrm{p}<0.05)$.

Conclusion: prone positioning increases IOP. In patients with prone position with a head rotation of 450 laterally, IOP in the upper positioned eye was significantly lower.

๑ 2013 Sociedade Brasileira de Anestesiologia. Published by Elsevier Editora Ltda. All rights reserved.
\end{abstract}

\section{Introduction}

Studies have shown that hypotension, anemia, obesity, peripheral vascular disease, and middle-aged men may be risk factors for the development of postoperative vision loss after surgery ${ }^{2,3}$. Prone positioning is also considered a risk factor because it increases intraocular pressure (IOP), which decreases perfusion pressure to the optic nerve ${ }^{1,4,5}$. The risk of postoperative vision loss in patients undergoing spine surgery in prone position is $0.05 \%{ }^{1}$. Some studies investigated the effects of head elevation in prone position to ameliorate the increase in IOP and had concluded that head elevation

*Corresponding author: Ege University School of Medicine Department of Anesthesiology and Reanimation 35100 Izmir-Turkey. Phone: +902323902142, FAX: +902323757321

E-mail: mnurideniz@hotmail.com

ISSN/\$ - see front metter @ 2013 Sociedade Brasileira de Anestesiologia. Published by Elsevier Editora Ltda. All rights reserved. 
may cause a decrease in IOP ${ }^{6}$. Although primary open angle glaucoma is a bilateral disease, glaucomatous defects are usually asymmetrical between the two eyes and one eye is more affected than the fellow eye. There are also situations like diabetic retinopathy where the walls of the blood vessels are affected and the change in perfusion during perioperative period may deteriorate the perfusion of the eye.

Percutaneous nephrolithotomy (PCNL) - performed in prone position - has become the gold standard for managing large and complex renal calculi ${ }^{7}$. The aim of our study was to compare preoperative and immediately postoperative IOP in patients undergoing PCNL in prone position and the effect of head rotation $45^{\circ}$ laterally in prone position on the increase in IOP of upper placed and lower placed eyes in patients undergoing PCNL. Our hypothesis is that head rotation $45^{\circ}$ laterally in prone position may prevent the increase in IOP of the upper positioned eye and may protect the more severely affected eye in situations like glaucoma.

\section{Materials and Methods}

After approval by institutional ethics committee and acquiring written informed patient consent of 45 patients (American Society of Anesthesiologists physical status I-II), aged between 18-80 years, they were scheduled for PCNL in the prone position in the Department of Urology. Patients with preexisting eye disease or previous eye surgery, Diabetes Mellitus, peripheral vascular disease, eye trauma or injury were excluded from the study. Patients were randomly allocated into 2 groups using a computer-generated list: Group I $(n=23)$ and Group II $(n=22)$. Before the study, intravenous catheters and standard anesthetic monitors (i.e., blood pressure cuff, electrocardiograph, and pulse oximeter) were placed in all patients. Anesthesia protocol was standardized for all study patients. After induction of anesthesia with propofol $2 \mathrm{mg} . \mathrm{kg}^{-1}$, remifentanil $1 \mu \mathrm{g} . \mathrm{kg}^{-1}$, and rocuronium $0.6 \mathrm{mg} \cdot \mathrm{kg}^{-1}$ intravenously, and ventilation with $\mathrm{O}_{2}$-air-sevoflurane via a facemask; the same anesthesiologist performed tracheal intubation. After intubation, the same ophthalmologist as before the operation had started (preoperative values) measured patient IOP bilaterally in supine position. IOP measurement was performed using Perkins Tonometer MK2 Clement clarke (Protected worldwide patents USA 5012812 ENGLAND). Urinary catheters were placed and patients were turned to prone position. The head was placed on a silicone headrest without external direct compression to both eyes, and the neck was in the midline position. Patients in Group I were kept in this prone position whereas patients in Group II were placed in the prone position with their heads rotated $45^{\circ}$ laterally to the right side. Anesthesia was maintained with 02 -air-sevoflurane and remifentanil $\left(0.25-1.0 \mu \mathrm{g} . \mathrm{kg}^{-1} \cdot \mathrm{min}^{-1}\right)$. Standard vital parameters, including blood pressure, $\mathrm{ECG}, \mathrm{SpO}_{2}$, and $\mathrm{EtCO}_{2}$ (end-tidal carbon dioxide) were monitored throughout the perioperative period. Mean arterial pressure was measured from the arm every 5 minutes and was kept within $20 \%$ of awake value, and ventilation was adjusted to keep EtCO2 in the range of 30 to $35 \mathrm{~mm} \mathrm{Hg}$ throughout the intraoperative period. All fluids administered were recorded, and estimated blood loss and urine output were measured to prevent over hydration. At the end of the operation, patients were turned to supine position and their IOP was measured immediately (postoperative values).

In Group I, bilateral measurements were recorded and IOP of the right eye was used for comparison. In Group II, IOP in upper (Group Ilu) and lower (Group IId) positioned eyes were recorded separately. We noted the length of time in the prone position. We recorded hematocrit for each patient preoperatively and postoperatively. Prospective power analysis revealed that a group size of approximately 22 patients in each group would have been required to identify significant difference between two groups with $95 \%$ power and $p=0.05$. Paired Samples test was used for the comparison within each group whereas Independent Samples Test was used for the comparison between groups.

\section{Results}

Every patient in each group completed the trial. Groups were comparable with respect to their demographic data, duration of surgery, fluid input and blood loss (Table 1). None of the patients reported any eye complaints after surgery. None of the patients required blood transfusion. Vital parameters were within normal limits through the surgery in both groups.

Table 1 Demographic and intraoperative data.

\begin{tabular}{lll}
\hline & Group I $(\mathrm{n}=23)$ & Group II $(\mathrm{n}=22)$ \\
\hline Age $(\mathrm{y})$ & $46 \pm 16$ & $52 \pm 12$ \\
Gender (M/F) & $16 / 7$ & $17 / 5$ \\
Weight $(\mathrm{kg})$ & $75 \pm 18$ & $80 \pm 13$ \\
Height $(\mathrm{cm})$ & $174 \pm 6$ & $173 \pm 6$ \\
Duration of surgery $(\mathrm{min})$ & $120 \pm 35$ & $90 \pm 44$ \\
Blood loss $(\mathrm{mL})$ & $120 \pm 32$ & $100 \pm 40$ \\
Fluid input $(\mathrm{mL})$ & $1,380 \pm 597$ & $1,600 \pm 571$ \\
\hline
\end{tabular}

Data are presented as mean \pm SD; ${ }^{*} \mathrm{p}<0.05$. 
Table 2 Intraocular pressure values $(\mathrm{mmHg})$ in two groups before and after the surgery.

\begin{tabular}{|c|c|c|c|}
\hline & Preoperative & Postoperative & $\mathrm{p}$ value \\
\hline Group I $(n=23)$ & $12.43 \pm 4.52$ & $18.21 \pm 5.73 \dagger$ & $0.001^{*}$ \\
\hline Group Ilu (n = 22) & $12.31 \pm 3.38$ & $14.95 \pm 4.64$ & $0.037^{*}$ \\
\hline Group IId $(n=22)$ & $12.36 \pm 3.38$ & $20.40 \pm 5.15 \dagger$ & $0.001^{*}$ \\
\hline
\end{tabular}

Intraocular pressure values after the surgery in prone position increased significantly compared to preoperative values in both groups $(p<0.05)$ (Table 2$)$. After surgery in prone position IOP values in Group Ilu (upper positioned eyes) were significantly lower than Group I and Group IId (lower positioned eyes) $(p<0.05)$. After surgery in prone position there was no significant difference in IOP values in Group I and Group IId (Table 2).

\section{Discussion}

The results of our study showed that upon prone positioning, the IOP significantly increased in patients undergoing PCNL. These findings are in accordance with previous studies ${ }^{8,9}$. Our results have also suggested that when patients were positioned prone with their heads rotated $45^{\circ}$ laterally, IOP in the upper positioned eyes were significantly lower than lower positioned eyes and IOP of the patients positioned prone without head rotation. The idea of head elevation being associated with less increase in IOP in prone position is not new, but our study is original in that it is the first to compare IOP of patients in the prone flat versus prone position with head rotation laterally. Since upper positioned eyes had significantly lower IOP values compared with strictly neutral prone position and lower position eyes, head rotation may have advantages for patients with glaucoma to protect a more severely affected eye. However, excess rotation should be avoided to prevent twisting the internal jugular vein with subsequent increase in venous pressure and IOP. It is also important to use appropriate silicone headrests to avoid direct eyeball compression because there should be no contact with headrest and orbita.

The study by Cheng et al. ${ }^{8}$ was the first study to measure IOP in prone anesthetized patients undergoing spinal surgery. They examined the combined effects of general anesthesia and the prone position on IOP in patients undergoing spine surgery. They found that prone positioning increased IOP during anesthesia. Since ocular perfusion pressure is commonly defined as the difference between mean arterial pressure (MAP) and IOP, the authors drew attention to the fact that ocular perfusion pressure could decrease despite maintenance of normotension during surgery in prone position ${ }^{8}$. In a similar study, Hunt et al. ${ }^{9}$ also studied patients undergoing spinal surgery and found that IOP increased when anesthetized patients are placed in prone position. Those in prone positions were significantly higher than supine positions.
Some studies have shown that Trendelenburg position in prone resulted in further increase in IOP compared to prone position ${ }^{1,6}$. Head elevation in prone position (reverse Trendelenburg) ameliorated the increase in IOP in prone flat ${ }^{6}$. Ozcan et al. ${ }^{6}$ studied the effect of body inclination during prone positioning on intraocular pressure in awake volunteers. They showed that a $10^{\text {th }}$ reverse Trendelenburg position ameliorated the increase in IOP caused by the prone position in awake volunteers. Although that study did not include all the factors that might have affected the IOP in an operative setting, it suggested a strategy to positively influence the IOP by changing the operating table inclination for patients in the prone position ${ }^{6}$.

The current study is original in that it is the first study to compare IOP of subjects in prone position with head rotation $45^{\circ}$ laterally. This study's main finding is that head rotation has an advantage on the upper positioned eyes without causing further disadvantage on the lower positioned eyes. This position may be particularly advantageous for patients with glaucoma to prevent the increase in IOP when head rotation $45^{\circ}$ laterally in prone position is used and the more severely affected eye is kept in the upper position. The asymmetry of visual field loss between eyes in primary angle closure glaucoma (PACG) and primary open angle glaucoma (POAG) was described by Wang et al. ${ }^{10}$. A more marked thinning of the neuroretinal nerve fiber layer in the eye with the higher IOP has also been described in normal-tension glaucoma patients ${ }^{11}$. Interocular asymmetries in IOP must be kept in mind especially in glaucoma patients in certain circumstances, such as operations under prone position and the eye with more severe glaucoma damage can be protected during the operation.

In conclusion, prone positioning increases IOP. When patients were positioned prone with heads rotated $45^{\circ}$ laterally, IOP in the upper positioned eyes were significantly lower than lower positioned eyes and prone position without head rotation. This position may be advantageous for patients with bilateral glaucoma to protect the more severely affected eye as well as unilateral glaucoma.

\section{References}

1. Walick KS, Kragh JE Jr, Ward JA, Crawford JJ - Changes in Intraocular Pressure due to Surgical Positioning Studying Potential Risk for Postoperative Vision Loss, Spine, 2007;32:25912595. 
2. Abraham M, Sakhuja N, Sinha S, Rastogi S - Unilateral visual loss after cervical spine surgery. J Neurosurg Anesthesiol, 2003;15:319-322.

3. Lee L, Lam A - Unilateral blindness after prone lumbar spine surgery. Anesthesiology, 2001;95:793-795.

4. Locastro A, Novak K, Biglan A - Central retinal artery occlusion in a child after general anesthesia. Am J Ophthalmol, 1991;112:9192.

5. Roth S, Nunez R, Schreider B - Unexplained visual loss after lumbar spinal fusion. J Neurosurg Anesthesiol, 1997;9:346348.

6. Ozcan MS, Praetel C, Bhatti MT, Gravenstein N, Mahla ME, and Seubert $\mathrm{CN}$ - The effect of body inclination during prone positioning on intraocular pressure in awake volunteers: a comparison of two operating tables. Anesth Analg, 2004;99:11521158.
7. Deane LA, Clayman RV - Advances in percutaneous nephrostolithotomy. Urol Clin North Am, 2007;34:383-395.

8. Cheng MA, Todorov A, Tempelhoff R, McHugh T, Crowder CM, Lauryssen $C$ - The effect of prone positioning on intraocular pressure in anesthetized patients. Anesthesiology, 2001;95:13511355.

9. Hunt K, Bajekal R, Calder I, Meacher R, Eliahoo J, Acheson JF Changes in intraocular pressure in anesthetized prone patients. J Neurosurg Anesthesiol, 2004;16:287-290.

10. Wang JC, Gazzard G, Foster FJ, et al - Interocular asymmetry of visual field defects in primary open angle glaucoma and primary angle-closure glaucoma. Eye, 2004;18:365-368.

11. Gugleta K, Orgül S, Flammer J - Asymmetry in intraocular pressure and retinal nerve fiber layer thickness in normaltension glaucoma. Ophthalmologica, 1999;213:219-223. 